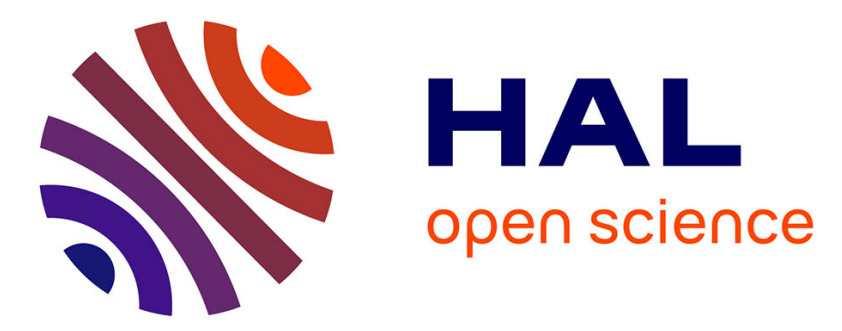

\title{
Small-molecule activation with iron porphyrins using electrons, photons and protons: some recent advances and future strategies
}

\author{
Elodie Anxolabéhère-Mallart, Julien Bonin, Claire Fave, Marc Robert
}

\section{- To cite this version:}

Elodie Anxolabéhère-Mallart, Julien Bonin, Claire Fave, Marc Robert. Small-molecule activation with iron porphyrins using electrons, photons and protons: some recent advances and future strategies. Dalton Transactions, 2019, 48 (18), pp.5869-5878. 10.1039/C9DT00136K . hal-02316700

\section{HAL Id: hal-02316700 \\ https://hal-univ-paris.archives-ouvertes.fr/hal-02316700}

Submitted on 15 Oct 2019

HAL is a multi-disciplinary open access archive for the deposit and dissemination of scientific research documents, whether they are published or not. The documents may come from teaching and research institutions in France or abroad, or from public or private research centers.
L'archive ouverte pluridisciplinaire HAL, est destinée au dépôt et à la diffusion de documents scientifiques de niveau recherche, publiés ou non, émanant des établissements d'enseignement et de recherche français ou étrangers, des laboratoires publics ou privés. 


\title{
Small-molecule activation with iron porphyrins using electrons, photons and protons: some recent advances and future strategies
}

\author{
Elodie Anxolabéhère-Mallart, (D) Julien Bonin, (D) Claire Fave (D) and Marc Robert (DD* \\ Substituted tetraphenyl Fe porphyrins are versatile molecular catalysts for the activation of small mole- \\ cules (such as $\mathrm{O}_{2}, \mathrm{H}^{+}$or $\mathrm{CO}_{2}$ ), which could lead to renewable energy storage, the direct production of \\ fuels or new catalytic relevant processes. Herein, we review the recent studies of these earth-abundant \\ metal catalysts for the electrochemical activation of dioxygen on the one hand and for the photostimu- \\ lated reduction of carbon dioxide on the other hand. These two prototype reactions illustrate how \\ mechanistic studies are the only rational approach to gain fundamental insights into the elementary steps \\ that drive the catalysis and for identification of the key intrinsic parameters controlling the reactivity, \\ offering in turn the possibility to rationally tune the structure of the catalysts as well as the catalytic \\ conditions.
}

\section{Introduction}

Nature has developed systems that are able to harness the oxidizing power of $\mathrm{O}_{2}$ to produce energy (e.g. in the aerobic respiration process) and chemical compounds (e.g. in various oxygenation process, such as those encountered in oxygenase activity). In these processes, kinetic barriers prevent $\mathrm{O}_{2}$ from reacting with organic substrates and being reduced to $\mathrm{H}_{2} \mathrm{O}$. These barriers, therefore, must be overcome in order to exploit and control the reactivity. The same is true regarding $\mathrm{CO}_{2}$ activation, which has been included by nature as a substrate for photosynthesis, ultimately generating chemical energy (under the form of carbohydrates) to fuel the activity of photosynthetic organisms. During the multi-electron and multi-proton processes that lead to reduced products, catalysis is mandatory to overcome the kinetic barriers and to achieve selectivity control.

Among the many molecular catalysts, iron tetraphenyl porphyrin complexes (Fig. 1) have long been used as homogeneous and heterogeneous Oxygen Reduction Reaction (ORR) or oxygen activation catalysts, as well as in $\mathrm{CO}_{2}$ reduction processes. As far as $\mathrm{O}_{2}$ is concerned, recent reviews on heterogeneous ${ }^{1}$ and homogeneous ${ }^{2}$ cases have detailed the nature of catalytic systems, including a description of many Fe porphyrins. The early development of Fe porphyrins catalysts for $\mathrm{O}_{2}$ activation stem from efforts to mimic the enzymatic activity

Université Paris Diderot, Sorbonne Paris Cité, Laboratoire d'Electrochimie Moléculaire, UMR 7591 CNRS, 15 rue Jean-Antoine de Baïf, F-75205 Paris Cedex 13, France.E-mail: robert@univ-paris-diderot.fr related to the uses of $\mathrm{O}_{2}$, such as $\mathrm{O}_{2}$ reduction in cytochrome c oxidase or $\mathrm{O}_{2}$ activation for the oxidation reaction in cytochrome $\mathrm{P} 4500^{3,4} \mathrm{Fe}$ porphyrins are capable of facilitating oxygen activation by an inner-sphere reaction, essentially through the binding of $\mathrm{O}_{2}$ to $\mathrm{Fe}(\mathrm{II})$ ion in concert with an electron transfer from $\mathrm{Fe}$ to $\mathrm{O}_{2}$ leading to the concomitant oneelectron reduction of $\mathrm{O}_{2}$ and the oxidation of $\mathrm{Fe}$ (II) to $\mathrm{Fe}$ (III) (i.e. formation of the superoxo adduct Fe(III)OO'). The development of new Fe porphyrins-based catalysts aim at two objectives: (1) improving the efficiency of the $4 \mathrm{e}^{-}$reduction of $\mathrm{O}_{2}$ to $\mathrm{H}_{2} \mathrm{O}$ in fuel cells, and (2) realizing $\mathrm{O}_{2}$ activation through partial and controlled reduction of $\mathrm{O}_{2}$ bound at the Fe active site. This activation occurs via sequential $\mathrm{e}^{-}$and $\mathrm{H}^{+}$transfers

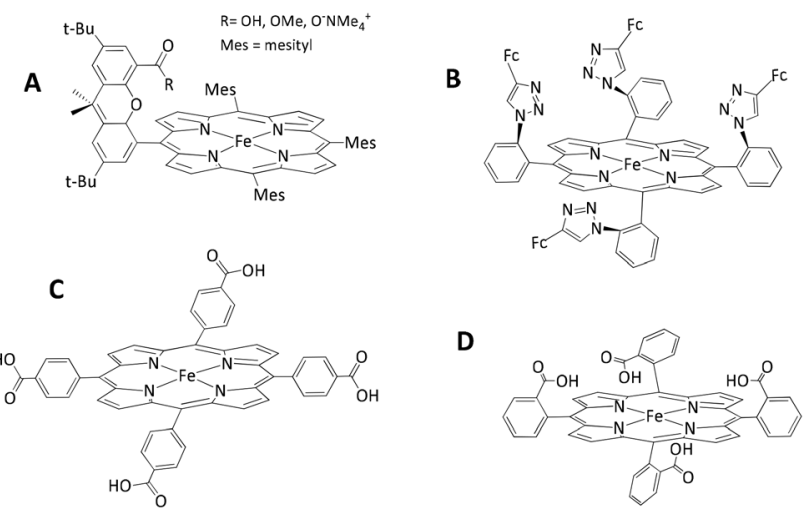

Fig. 1 Schematics of: (A) hangman porphyrins, ${ }^{20}$ (B) the $\alpha_{4}-\mathrm{FeFc}_{4}$ complex, $^{21}$ (C) and (D) Fe(III) 5,10,15,20-tetrakis (carboxyphenyl) porphyrins. $^{22}$ 
to realize $\mathrm{O}-\mathrm{O}$ bond cleavage and to generate a high-valent reactive Fe-oxo species capable of oxidizing organic substrates. In the first section of this perspective, we review recent papers dealing with electrochemical $\mathrm{O}_{2}$ reduction/activation using $\mathrm{Fe}$ porphyrins. We emphasize that the inhomogeneity of the experimental conditions (i.e. aqueous or organic medium, covalently bound to an electrode, or solubilized molecular catalyst, and so on) prevents any direct comparison of the performances of the various systems.

Remarkably, the role of iron tetraphenyl porphyrins as molecular catalysts for small-molecule activation is of course not restricted to $\mathrm{O}_{2}$-containing systems. These bio-inspired complexes also bind carbon oxides; for example, Fe(II) species strongly interact with $\mathrm{CO}$, while the nucleophilic $\mathrm{Fe}(0)$ quickly coordinates to $\mathrm{CO}_{2}$, which opens up a rich catalytic chemistry to the multi-electrons and multi-protons reduction of gases. The catalytic processes for $\mathrm{CO}_{2}$ reduction are generally of the ECEC or ECCE type (where $\mathrm{E}$ is an electron transfer step and $\mathrm{C}$ a chemical reaction (here protonation)), parallelling catalytic schemes observed for $\mathrm{O}_{2}$ reduction, although the oxidation states of the iron centre are not the same for the two reactions. A method of choice for the clean generation of $\mathrm{Fe}(0)$ is electrochemistry, which has been extensively used since the pioneering work of Savéant et $a l .{ }^{5}$ It has also led to important mechanistic insights and in some cases to a deep understanding of the elementary steps of catalysis. ${ }^{6-8}$ The mechanistic knowledge helped tuning the substituents on the phenyl rings of the ligand and optimizing the performances. In particular, the derivatives bearing either - $\mathrm{OH}$ groups or positively charged trimethylammonio groups on the phenyl moieties (Fig. 4) proved to be among the best molecular catalysts for the $\mathrm{CO}_{2}$-to-CO conversion, both in terms of selectivity (close to $100 \%$ ), intrinsic rate and long-term stability (several days in the best cases). ${ }^{9-11}$ Catalysts are highly active in organic solvent and in water as well.

Inspired by these studies, we developed a homogeneous photostimulated approach for achieving the visible lightdriven reduction of $\mathrm{CO}_{2} \cdot{ }^{12,13}$ In such an approach, the electrode is replaced by a molecular sensitizer that absorbs photons, while electrons are ultimately provided by a sacrificial donor. Following a parallel strategy to the electrochemical studies, i.e. developing a rational, methodic mechanistic approach, we have been able in the last 5 years to devise systems for the efficient and selective catalysis of the $\mathrm{CO}_{2}$, not only to $\mathrm{CO}$ in organic solvent and aqueous solutions, but also to more reduced products, such as methane, employing only an earth-abundant metal and a simple organic sensitizer. These studies will be the object of the second section of this perspective.

\section{Electrochemical activation and reduction of $\mathrm{O}_{2}$}

It is now well established that there is a strong correlation between the structure of the catalyst and its oxygen activation or ORR catalytic activity. In this sense, coordination of an axial ligand, modification of the secondary coordination by an acidic group and physisorption or grafting of the catalyst on a surface actively participate in the catalytic activity.

\section{$\mathrm{O}_{2}$ binding to $\mathrm{Fe}$ porphyrins}

$\mathrm{O}_{2}$ binding to the $\mathrm{Fe}$ centre is the first step in the activation process. DFT calculations ${ }^{14}$ have been performed for better understanding the mechanism of the reversible $\mathrm{O}_{2}$ binding by heme. It has been demonstrated that $\mathrm{O}_{2}$ is in its singlet state when coordinating to the metal. Although this aspect has not yet been systematically explored, several studies have evidenced that the nature of the ligand trans to the $\mathrm{O}_{2}$ binding plays a role in the reactivity of the $\mathrm{Fe}(\mathrm{III})$-superoxo $\mathrm{Fe}(\mathrm{III}) \mathrm{OO}^{*}$ adduct. The effects of axial ligands ("push effect") on the electronic structure and $\mathrm{O}_{2}$ reduction have been reported in a recent review in which the authors discuss the ground state electronic structure of $\mathrm{Fe}$ porphyrins bearing various axial ligands (imidazole, phenolate and thiolate). ${ }^{15}$ In this work, through the analysis of the differences in kinetics and selectivity for ORR, the authors present a quantitative understanding of the push effect, i.e. the ability of axial ligands to activate the O-O bond cleavage through an electron-donating effect. A DFT calculation study by Kasai suggested that imidazole ligand axial coordination weakens the $\mathrm{O}-\mathrm{O}$ bond in $\mathrm{O}_{2}$ adducts, thus favouring $4 \mathrm{e}^{-} \mathrm{O}_{2}$-reduction catalysis. ${ }^{16} \mathrm{~A}$ related study by Naruta et al. reported that the formation of the Fe(III)-hydroperoxo $(\mathrm{Fe}(\mathrm{III}) \mathrm{OOH})$ reactive species involved in the $\mathrm{O}-\mathrm{O}$ bond cleavage reaction is enhanced thanks to the increase of the $\mathrm{p} K_{\mathrm{a}}$ values of $\mathrm{Fe}(\mathrm{III}) \mathrm{OO}^{*}$ and $\mathrm{Fe}(\mathrm{III}) \mathrm{OO}$ species resulting from imidazole axial coordination to the iron ion. ${ }^{17}$

\section{Ligand modification and secondary coordination sphere effects}

From early studies by Momenteau ${ }^{4}$ and Collman $^{18}$ and inspired by the protein environment of metalloenzyme active sites, the rational design of porphyrin ligands has allowed for the development of more sophisticated structures. Advances in porphyrin- and corrole-based ORR catalysts were addressed thoroughly in a recent review by Cao. ${ }^{19}$ In particular, Fe porphyrin complexes with hydrogen-bonding groups in the secondary coordination sphere have been synthesized, such as the so-called hangman porphyrins (Fig. 1A) developed by Nocera, ${ }^{20}$ showing an enhancement of $\mathrm{O}_{2}$ activation. These systems allow tuning the acid-base properties of bound $\mathrm{O}_{2}$ intermediates, and it was shown that protonation control of these intermediates plays a crucial role in $\mathrm{O}-\mathrm{O}$ bond cleavage.

Electrochemical $\mathrm{O}_{2}$ catalytic activation using $\mathrm{Fe}$ porphyrins has been studied both in aqueous and in organic media. Recent studies of water soluble Fe(III) tetra- $N$-methylpyridinium porphyrins have reported $\mathrm{O}_{2}$ to $\mathrm{H}_{2} \mathrm{O}$ reduction with high catalytic performance in $0.1 \mathrm{M}$ HOTf $\left(k_{\text {cat }}=6.04 \times 10^{4} \mathrm{M}^{-1} \mathrm{~s}^{-1}\right)$. Although this specific aspect was not further detailed, the authors observed an enhancement of the turnover frequency in the presence of protonated imidazole. ${ }^{23}$ Matson et al. also reported the $4 \mathrm{e}^{-} / 4 \mathrm{H}^{+}$reduction of $\mathrm{O}_{2}$ using $\mathrm{Fe}(\mathrm{III})$ tetra- $N$-pyri- 
dinium porphyrins derivatives with high selectivity $(<15 \%$ $\left.\mathrm{H}_{2} \mathrm{O}_{2}\right) .{ }^{24}$ Looking at another type of porphyrin ligand modification, Dey's group showed that electron-withdrawing ester groups in the $\beta$-pyrrolic position of $\mathrm{Fe}(\mathrm{III})$ tetraphenylporphyrin induce a positive shift $(200 \mathrm{mV})$ of the formal $\mathrm{Fe}(\mathrm{III}) / \mathrm{Fe}(\mathrm{II})$ potential in both organic and aqueous media and of the onset potential of ORR as compared to the unsubstituted porphyrin. $^{25}$

Electrochemical studies of $\mathrm{O}_{2}$ reduction in organic solvents have been mainly performed in $\mathrm{N}, \mathrm{N}$-dimethylformamide (DMF) and acetonitrile (ACN). After reporting ORR studies with the non-substituted archetype porphyrin $\mathrm{Fe}(\mathrm{III})(\mathrm{TPP}) \mathrm{Cl}$ $(\mathrm{TPP}=5,10,15,20$-tetraphenylporphyrin, Fig. 4$),{ }^{26}$ Mayer et al. studied the influence of the local proton source in the secondary coordination sphere with $\mathrm{Fe}(\mathrm{III})$ 5,10,15,20-tetrakis (carboxyphenyl)porphyrins incorporating carbonyl groups in the ortho and para positions (Fig. 1C and D). The authors reported a higher selectivity for $\mathrm{H}_{2} \mathrm{O}$ production in the case of the orthosubstituted derivative, which was attributed to the involvement of the carboxylic groups as protonating agents or proton relays. ${ }^{22}$ In a more recent analysis of the ORR performance within a series of Fe porphyrins, Mayer's group showed experimental evidence, supported by computational studies, that the free energies for $\mathrm{O}_{2}$ binding to the Fe were linearly correlated to the catalyst $E_{1 / 2}$ reduction potential. From this analysis, they demonstrated that decoupling of the properties of the first coordination sphere $\left(E_{1 / 2}, K_{\mathrm{O}_{2}}\right)$ from the influence of the second coordination sphere (basicity of the superoxide intermediate, $\mathrm{p} K_{\mathrm{a}}$ ) seems to be a promising way to overcome the scaling relationship and thus to facilitate the design of new, efficient catalysts. $^{27}$

In this period, Dey's group also made an important contribution to the $\mathrm{O}_{2}$ electrochemical activation studies with various $\mathrm{Fe}$ porphyrin derivatives, with catalysts in solution (homogeneous conditions) or with surface-modified electrodes. Using the $\alpha_{4}-\mathrm{FeFc}_{4}$ porphyrin complex (Fig. 1B), they analyzed the role of the secondary coordination sphere effect for facilitating ORR catalysis. ${ }^{21,28,29}$ They found that the $\alpha_{4}-\mathrm{FeFc}_{4}$ complex could act both as a homogeneous catalyst (in an organic solvent in the presence of acid) and as a heterogeneous catalyst (in an aqueous medium, $\mathrm{pH}$ 1-9) for ORR, and proposed that the triazole residues offer an efficient proton-transfer pathway into the active site.

\section{Influence of the electrode surface}

Since Collman's early work with a catalytic system attached to an electrode, ${ }^{30,31}$ surfaces have proven to be an efficient interface to tune and to boost $\mathrm{O}_{2}$ activationas well as to study intermediatespecies. In some cases, the surface itself or a surface modified either by an organic molecule or by a polymer can be considered as an "axial" ligand. ${ }^{32}$ In a similar way, Chlistunoff and Sansinena reported a $300 \mathrm{mV}$ positive shift of the $\mathrm{O}_{2}$ reduction in an acidic medium for a catalytic system corresponding to a mixture of Fe porphyrin and carbon Vulcan impregnated with polyvinylimidazole in comparison with the catalyst in solution or supported on graphene surface. ${ }^{33}$ An original approach used a honeybee silk film as the surface. The presence of the silk films favoured cleavage of the $\mathrm{O}-\mathrm{O}$ bond by playing the role of an axial ligand to the heme centre. ${ }^{34}$ Costentin et al., revisiting the catalytic activity of the extensively studied para derivative of Fe(III) 5,10,15,20-tetrakis ( $N$-methylpyridyl)porphyrin, recently showed that although the amount of adsorbed catalyst on a glassy carbon electrode was very small, the catalytic activity found its origin in the heterogeneous contribution over the homogeneous contribution $\left(k_{\text {het }}\right.$ $\left.=780 \mathrm{~s}^{-1}, k_{\mathrm{hom}}=30 \mathrm{~s}^{-1}\right) .{ }^{35}$ Liu and co-workers reported another approach by anchoring biomimetic ORR electrocatalysts onto the surface through a pre-functionalization with imidazole derivatives, which led to a remarkably high ORR activity. A DFTPPFe porphyrin (DFTPP = 2,6-difluorotetraphenylporphyrin) was grafted onto multi-walled carbon nanotubes (MWCNTs) surface previously modified by imidazole through the axial position (Fig. 2). The ORR catalytic activities of the DFTPPFe-Im-CNTs, DFTPPFe-CNTs (a simple mixture of the porphyrin and CNTs) and the Pt/C catalyst were studied and compared by using a rotating ring-disc electrode. The DFTPPFe-Im-CNTs exhibited a higher ORR activity (high selectivity in the direct $4 \mathrm{e}^{-} / 4 \mathrm{H}^{+}$reduction) and also superior stability $(90 \%$ of the initial current for the DFTPPFe-Im-CNTs is retained compared to only $57 \%$ for the $\mathrm{Pt} / \mathrm{C}$ catalyst under the same conditions). ${ }^{36}$

Dey also reported the use of ammonium tetrathiomolybdate (ATM) for forming self-assembled adlayers on gold electrodes, which are robust and stable in aqueous environments and can be used to physisorb Fe porphyrin catalysts. The modified electrodes showed better performance in terms of stability during the hydrodynamic electrochemical experiments unlike the selfassembled monolayer (SAM) of thiols on Au/Ag. The rate of interfacial charge transfer could be tuned by controlling the thickness of the ATM layer by varying the deposition time. ${ }^{37}$

Very recently, Elbaz and co-workers used a modified graphene oxide surface with benzimidazole and reacted it with a

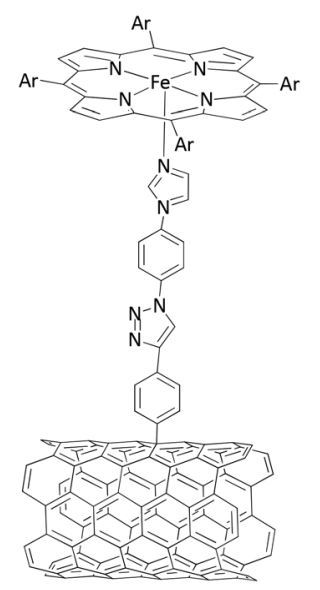

Fig. 2 Schematic representation of the bio-inspired ORR catalyst (DFTPP)Fe-Im-CNTs (Ar = aryl) covalently anchored to the surface of multiwalled CNTs. ${ }^{36}$ 
Fe(III)tetrakis(1-methyl-4-pyridyl)porphyrin. The presence of this surface bound-axial ligand boosted the $4 \mathrm{e}^{-} / 4 \mathrm{H}^{+}$reduction by facilitating the reduction of peroxide anion. ${ }^{38}$

Finally, one may note the work of Mayer and co-workers who evaluated the performance of several substituted Fe porphyrin complexes for ORR electrocatalysis in different homogeneous and heterogeneous media. They observed that the selectivity for $4 \mathrm{e}^{-}$reduction to $\mathrm{H}_{2} \mathrm{O}$ vs. $2 \mathrm{e}^{-}$reduction to $\mathrm{H}_{2} \mathrm{O}_{2}$ varied substantially from one medium to another for a given catalyst. One important conclusion of this work is that any comparison of the selectivity results from supported and soluble molecular ORR electrocatalysts must be interpreted with caution, as selectivity is a property not only of the catalyst structure (which notably includes the presence or not of a proton relay on the porphyrin ligand) but also the nature of the surrounding medium (solvent, acido-basic species and nature of the film in case of supported catalysis). ${ }^{39}$

\section{Detection of intermediates and mechanistic insights}

In order to gain insights into the mechanism of Fe porphyrin electrocatalysts reducing $\mathrm{O}_{2}$, Dey and co-workers developed a set-up for coupling a rotating disc (RDE) or rotating-ring-disc electrochemistry (RRDE) with resonance Raman spectroscopy. The studies were conducted in buffered aqueous solutions with Fe catalyst immobilized on a thiol SAM-covered Au disc electrode though axial ligand binding (thiolate, imidazole). These experiments probed the system under steady state conditions. A combination of oxidation and spin-state marker bands and metal ligand vibrations provided for the in situ identification of $\mathrm{O}_{2}$-derived intermediates formed on the electrode surface. ${ }^{40,41}$ Interestingly with the system where a thiolate was bound to the Fe center, highly oxidizing species were generated at the electrode during electrocatalytic $\mathrm{O}_{2}$ reduction. These reactive species could in principle act as an oxidant for triggering catalytic processes. ${ }^{32,42,43}$ Upon combining the same SERRS-RDE (SERRS: surface enhanced resonance Raman spectroscopy) method with a measurement of the H/D isotope effects, the group recently reported that the rate of $\mathrm{O}_{2}$ reduction, $\sim 10^{4}$ to $10^{5} \mathrm{M}^{-1} \mathrm{~s}^{-1}$ for simple Fe porphyrins, was limited by the $\mathrm{O}-\mathrm{O}$ bond cleavage rate of a ferric peroxide intermediate species. SERRS-RDE probes the system in operando when it is under steady state conditions, such that any species that has a faster formation rate as compared to its decay rate, including the rate determining species, would accumulate and can be identified. It is also reported that the selectivity of the ORR is determined by the protonation site of the ferric peroxide intermediate and can be controlled by installing pre-organized second sphere residues in the distal pocket. The $4 \mathrm{e}^{-} / 4 \mathrm{H}^{+}$reduction of $\mathrm{O}_{2}$ entails protonation of the distal oxygen of the $\mathrm{Fe}^{\mathrm{III}}-\mathrm{OOH}$ species, while $2 \mathrm{e}^{-} / 2 \mathrm{H}^{+}$ reduction requires the proximal oxygen to be protonated. Very recently Dey and co-workers highlighted an unprecedented $4 \mathrm{e}^{-} / 4 \mathrm{H}^{+}$behaviour ( $>90 \%$ selectivity) of $\mathrm{Fe}$ porphyrin complexes containing a basic residue when adsorbed on EPG (edge pyrolytic graphite) electrodes. DFT calculations showed that the hydroperoxide is stabilized by H-bonding, resulting in an elongation of the $\mathrm{O}-\mathrm{O}$ bond and promotion of proton transfer to the distal oxygen. ${ }^{44}$

Finally, in a recent and detailed account incorporating all the recent studies based on the SERRS-RDE method, Dey and co-workers reviewed the various factors (e.g. the binding of axial ligands and incorporation of second coordination sites) determining the rate and selectivity of the electrocatalytic reduction of $\mathrm{O}_{2}$ by $\mathrm{Fe}$ porphyrin complexes. ${ }^{46}$ We have reported the electrochemical generation of the intermediates species $\mathrm{Fe}(\mathrm{III}) \mathrm{OO}$ peroxo and $\mathrm{Fe}(\mathrm{III}) \mathrm{OOH}$ hydroperoxo using simple commercially available Fe(III) tetrakis(pentafluorophenyl)porphyrin ( $\left.\mathrm{Fe}(\mathrm{III}) \mathrm{F}_{20} \mathrm{TPP}\right)$ in $\mathrm{DMF}$, thus mimicking the first step of $\mathrm{O}_{2}$ activation cycle (Fig. 3). The experimental set-up allowed the measurement of the oxidation potential of the peroxo ( $E=0.5 \mathrm{~V}$ vs. SCE) from the electroreduction of the superoxo adduct at a moderate potential $(-0.60 \mathrm{~V} v s$. SCE $)$ and the EPR detection of the hydroperoxo.

It is worth mentioning here that this electrochemical approach coupled to spectroscopy is an appropriate method to generate and characterize reactive species, ${ }^{45}$ complementary to the one reported by Dey.

The control of the reductive activation of $\mathrm{O}_{2}$ with bioinspired catalysts remains challenging, in particular for predicting the final products of the reaction, i.e. $\mathrm{H}_{2} \mathrm{O}, \mathrm{H}_{2} \mathrm{O}_{2}$ or $\mathrm{SO}$ (with $\mathrm{S}=$ substrate). Our ability to design a single catalyst so as to favour a specific product remains out of reach. In Nature, selectivity is controlled by the active site of the metalloenzyme yielding $\mathrm{H}_{2} \mathrm{O}\left(\mathrm{O}_{2}+4 \mathrm{e}^{-}+4 \mathrm{H}^{+} \rightarrow \mathrm{H}_{2} \mathrm{O}\right.$, cytochrome c oxidase $)$ or oxygenated molecules $\left(\mathrm{RH}+\mathrm{O}_{2}+2 \mathrm{e}^{-}+2 \mathrm{H}^{+} \rightarrow \mathrm{ROH}+\mathrm{H}_{2} \mathrm{O}\right.$, cytochrome $\mathrm{P} 450)$. In other words, tuning the exact structure of the ligand around the metal active site could allow triggering a specific reaction and the ability to discriminate between the two major pathways. Along these lines, we have shown in the above paragraphs that the use of electrochemical tools and techniques, through a precise adjustment of the electrode potential and control of the $\mathrm{pH}$, allows tuning the formation of some key intermediates and to further characterize them with complementary coupled spectroscopic methods. Although obtained on model systems that are not the most cat-

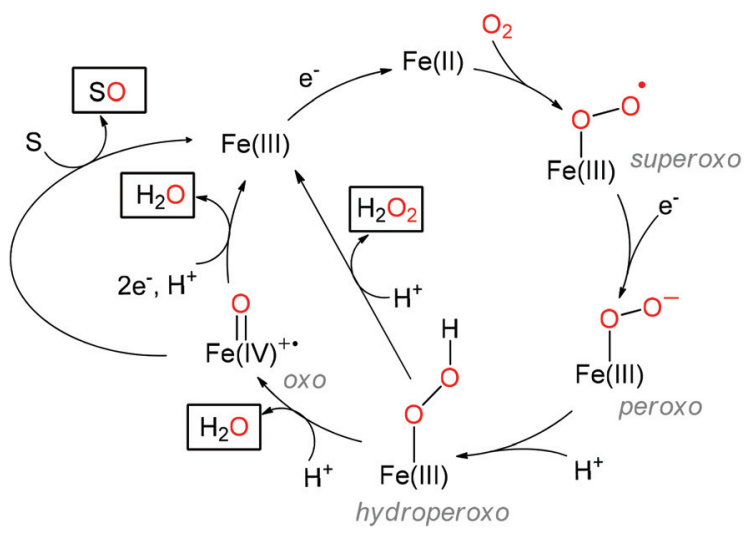

Fig. 3 Catalytic scheme for the electrochemical reductive activation of $\mathrm{O}_{2}$ and of the final products in the presence of iron porphyrin catalyst. ${ }^{45}$ 
alytically active ones, gathering all these data is a necessary step to better understand the reductive activation of $\mathrm{O}_{2}$ in the ORR reactions.

\section{Photostimulated reduction of $\mathrm{CO}_{2}$}

\section{Light-induced catalyst activation}

Following pioneering studies by Neta et al. in the early 1990 s $^{47-49}$ we have demonstrated in the last years that Fe porphyrins are efficient molecular catalysts for photochemically induced $\mathrm{CO}_{2}$ reduction to $\mathrm{CO}^{12,13,50}$ but also to $\mathrm{CH}_{4},{ }^{51}$ both in organic $^{52}$ and in aqueous ${ }^{53,54}$ environments. In this approach, a key aspect lies in efficient catalyst activation, which requires three successive electron transfers (ET) to the catalyst centre to reach the $\mathrm{Fe}(0)$ active state. Starting from the $\mathrm{Fe}(\mathrm{III})$ state, the first ET can occur through homolytic bond-breaking of the $\mathrm{Fe}-\mathrm{Cl}$ (eqn (1)) bond under irradiation of the ligand-to-metal charge transfer (LMCT) band of the porphyrin (around $330 \mathrm{~nm}$ ). The low efficiency of the process combined with the use of deleterious (see below) UV light makes it necessary to include a sacrificial electron donor (SD, eqn (2)), typically a tertiary amine. The yield and rate of formation of the Fe(II) state is then greatly enhanced. The two subsequent ETs, leading to $\mathrm{Fe}(\mathrm{I})$ and ultimately to $\mathrm{Fe}(0)$ species (eqn (3)-(5)), occur by a bimolecular reductive quenching reaction between the porphyrin excited state and the SD. The oxidation of the latter generates the $\mathrm{SD}^{-+}$radical cation, which undergoes a dismutation-like acid-base reaction (eqn (6)) and generates a reducing and reactive radical able to reduce another $\mathrm{Fe}(\mathrm{III})$ centre (eqn (7)). As a side reaction, the protonated form of SD is also formed in this process, which is a species that could play an important role in the mechanism, being a strong acid donor, as exposed later.

$$
\begin{gathered}
\mathrm{Fe}(\mathrm{III})-\mathrm{Cl} \stackrel{h v}{\longrightarrow} \mathrm{Fe}(\mathrm{II})+\mathrm{Cl}^{\bullet} \\
\mathrm{Fe}(\mathrm{III})^{+}+\mathrm{SD} \stackrel{h v}{\longrightarrow} \mathrm{Fe}(\mathrm{II})+\mathrm{SD}^{\bullet+} \\
\mathrm{Fe}(\mathrm{II})+\mathrm{SD} \stackrel{h v}{\longrightarrow} \mathrm{Fe}(\mathrm{I})^{-}+\mathrm{SD}^{\cdot+} \\
\mathrm{Fe}(\mathrm{I})^{-}+\mathrm{SD} \stackrel{h v}{\longrightarrow} \mathrm{Fe}(0)^{2-}+\mathrm{SD}^{\bullet+} \\
2 \mathrm{Fe}(\mathrm{I})^{-} \rightleftarrows \mathrm{Fe}(0)^{2-}+\mathrm{Fe}(\mathrm{II}) \\
\mathrm{SD}^{\bullet}+\mathrm{SD} \rightarrow \mathrm{SDH}^{+}+\mathrm{SD}-\mathrm{SD} \\
\mathrm{SD}^{\bullet}-\mathrm{SD}+\mathrm{Fe}(\mathrm{III})^{+} \rightarrow \mathrm{SD}^{+}-\mathrm{SD}+\mathrm{Fe}(\mathrm{II})
\end{gathered}
$$

The catalytic active $\mathrm{Fe}(0)$ species bind to $\mathrm{CO}_{2}$ and upon protonation and further reduction afford $\mathrm{CO}$ and a water molecule. Depending on the acid content of the solution ( $\mathrm{pK}$ and concentration) and of the nature of the substituents on the porphyrin ligand, the sequencing of electron and proton transfers and their degree of coupling (concerted vs. sequential steps) may vary.

\section{Catalysis analysis and quantification}

To analyse and quantify the catalytic performances, we made intensive use of a combination of spectroscopic and chromatographic studies. Collecting UV-Visible absorption spectra during the course (typically, several hours) of irradiation indeed allowed identifying some intermediates. This approach was, however, only tractable when no other absorbing species, such as a photosensitizer, was present in the reaction solution. We thus demonstrated that the formation of the Fe(II) could be readily achieved and that, upon defined conditions, Fe(I) and/ or Fe(II)-CO could be observed, meaning that these species somehow accumulated. $\mathrm{Fe}(0)$, being highly reactive, was formed in very low quantity and had a short lifetime, consequently it could not be observed spectroscopically. Moreover, the various $\mathrm{Fe}$ redox states of the porphyrin usually had similar and strong absorption spectra, mainly in the Soret band region, so that spectral overlap was frequently encountered. We were, however, able to attribute each Fe state to its spectral signature by conducting spectroelectrochemical measurements and using previously reported data. ${ }^{12,55}$ Spectroscopic measurement is also a pertinent tool to track for degradation of the system. It is known that the hydrogenation of the porphyrin macrocycle, leading to the parent chlorin and phlorin compounds, is associated with an increase in UV $(<300 \mathrm{~nm})$ absorption corresponding to the loss of ligand conjugation. Gas chromatography (GC), coupled (GC-MS) or not with mass spectrometry, was the second tool utilized for catalysis evaluation. By analysing the gas composition in the solution headspace along the irradiation course, it was possible to precisely quantify the number of catalytic turnover (TON) as well as the catalytic selectivity (CS) towards the detected products. The absence or presence of liquid products was checked by ionic chromatography or by NMR (formate, formaldehyde, methanol). Note that in all cases, checks that the reaction products were indeed issued from the $\mathrm{CO}_{2}$ were carefully performed by NMR or GC/MS, or both, upon photo-experiments with labelled ${ }^{13} \mathrm{CO}_{2}$.

\section{Catalyst structure and reaction partners}

The catalytic system used in the photochemical approach was a combination of several components, each of them being a potential lever to drive the process into the desired direction. The first element is the catalyst itself, and along years, several derivatives bearing various groups on the phenyl rings have been prepared in our lab. ${ }^{56,57}$ Structural modifications allow modulating the standard potential of the iron centre through an inductive (through structure) effect. A more positive standard potential of the $\mathrm{Fe}(\mathrm{I}) / \mathrm{Fe}(0)$ redox couple facilitates the electron-transfer step but at the expense of a decrease in the intrinsic activity of the reduced porphyrin(0).

Second coordination sphere effects, such as through space effects, can counterbalance the previous decrease. For example, the introduction of internal $\mathrm{OH}$ groups ( $\mathrm{Fe}-\mathrm{O}-\mathrm{OH}$ and Fe-o-OH-F10,Fig. 4) can provide H-bond stabilization of the $\mathrm{Fe}(0)-\mathrm{CO}_{2}$ adduct and canfurther act as a protonating agent. 

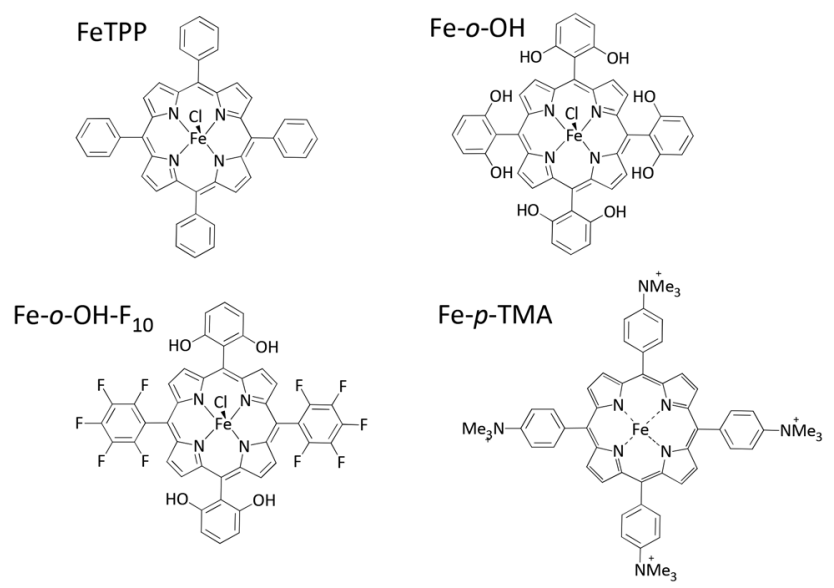

Fig. 4 Tetraphenyl Fe porphyrin catalysts for photostimulated $\mathrm{CO}_{2}$ reduction.

The introduction of positively charged groups (trimethylammonio groups) at the periphery of the phenyl rings (Fe-p-TMA, Fig. 4) can also lead toa stabilization of the partial negative charge borne by the $\mathrm{O}$ atoms of the $\mathrm{CO}_{2}$ inthe adduct. In these two cases, the intrinsic activity of the porphyrins is greatly enhanced. Another distinct advantage of using Fe-p-TMA is the possibility to perform the catalysis in water (see below)

(Table 1).

We equally explored various sacrificial electron donors (SD), starting from typical amines (TEA, TEOA, DiPEA) and using also very efficient donors, such as BIH (Fig. 5, bottom). A drawback is their degradation to by-products during catalysis. It is known that both tertiary amines and EDTA evolve, upon oxidation, into aminyl radicals and then to iminium species and, in the presence of water, to secondary amines and short aldehydes. ${ }^{59,60}$ Once oxidized, BIH quickly releases one proton and then a second electron to form a cationic dead-end species. ${ }^{60}$ To date, no detectable degradation of our system could be attributed to these secondary reactions.

To ensure an efficient visible light absorption and to allow irradiation in the visible range, several photosensitizers (PS), both inorganic and organic have been tested (Fig. 5, top and middle). Since $\mathrm{CO}_{2}$ reduction requires the concomitant transfer of several protons, external acids with various pK (water, phenol, trifluoroethanol) have been employed to enhance the catalysis, keeping in mind that a balance should be kept for the acid strength, since a too weak acid will only weakly boost the process while a too strong one may favour competitive hydrogen evolution. Finally, even if most of our studies have

Table 1 Standard redox potentials (V vs. SCE) for Fe porphyrins (in DMF) $)^{58}$

\begin{tabular}{lllll}
\hline & FeTPP & Fe-o-OH & Fe-o-OH-F & Fe- $p$-TMA \\
\hline $\mathrm{Fe}(\mathrm{III}) / \mathrm{Fe}(\mathrm{II})$ & -0.21 & -0.34 & -0.12 & -0.10 \\
$\mathrm{Fe}(\mathrm{II}) / \mathrm{Fe}(\mathrm{I})$ & -1.05 & -1.16 & -0.99 & -0.95 \\
$\mathrm{Fe}(\mathrm{I}) / \mathrm{Fe}(0)$ & -1.67 & -1.57 & -1.51 & -1.47
\end{tabular}

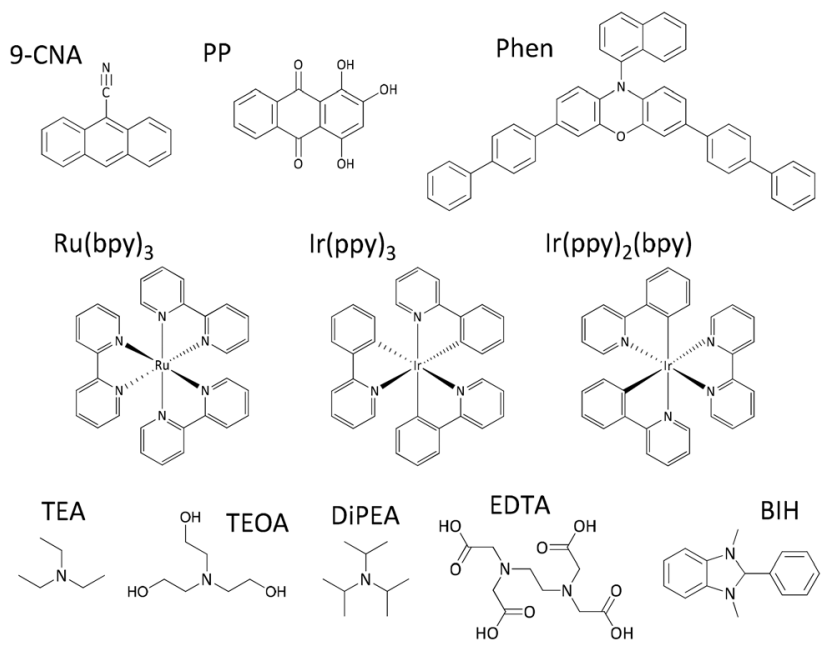

Fig. 5 Top, middle: Main organic and inorganic sensitizers employed for the $\mathrm{CO}_{2}$ photostimulated conversion. Bottom: Typically used sacrificial donors.

been performed in an organic solvent (acetonitrile) to ensure a suitable solubility of each component and particularly of $\mathrm{CO}_{2}$, we recently managed to carry out the photostimulated catalysis in aqueous solutions, which constitutes a key target for applications but still presents major challenges to be addressed.

\section{Photoinduced $\mathrm{CO}_{2}$ reduction to $\mathrm{CO}$}

In a first approach, the remarkable optical properties of Fe porphyrin were exploited to trigger a catalytic process without the assistance of a sensitizer, which remains rare in the literature. We started with the unmodified Fe tetraphenylporphyrin (FeTPP, Fig. 4) and with two analogues bearing - $\mathrm{OH}$ groups in all ortho, ortho' positions of the four phenyls (Fe-o-OH, Fig. 4), or $-\mathrm{OH}$ groups and $-\mathrm{F}$ atoms on the phenyl rings $\left(\mathrm{Fe}-\mathrm{o}-\mathrm{OH}-\mathrm{F}_{10}\right.$, Fig. 4). ${ }^{12}$ We showed that these three catalysts can achieve $\mathrm{CO}_{2}$ conversion to $\mathrm{CO}$ at a moderate rate and with limited selectivity. We also identified intrinsic limitations due to three factors. First, near-UV ( $c a .300 \mathrm{~nm}$ ) irradiation was required but induced a progressive photodegradation of the catalyst; then, a competitive pathway for $\mathrm{H}_{2}$ formation was observed thanks to the presence of the acidic protonated form of the SD; finally, modified porphyrins stabilized the adduct formed with $\mathrm{CO}_{2}$ but this made it necessary for the injection of an extra electron to cleave the $\mathrm{C}-\mathrm{O}$ bond, and no other species but $\mathrm{Fe}(0)$ itself, whose concentration was low, was reductive enough to achieve this step. More recently, another analogue bearing four positively charged trimethylammonio groups (Fe-p-TMA, Fig. 4) has been used in association with BIH (Fig. 5) as an $\mathrm{SD}^{50}$ First, we demonstrated that the introduction of the trimethylammonio groups made the catalyst active under visible light, preventing photodegradation. Second, the competitive $\mathrm{H}_{2}$ pathway was bypassed since selective $\mathrm{CO}$ formation was observed. Third, the four positively charged groups played a strong stabilizing role since no loss of activity, albeit modest, was observed over $60 \mathrm{~h}$ reaction. This was taken 
as evidence that the Fe- $p$-TMA analogue possessed key features for $\mathrm{CO}_{2}$ photostimulated reduction.

\section{Photoinduced $\mathrm{CO}_{2}$ reduction to $\mathrm{CH}_{4}$}

Having in hand a promising catalyst, we then combined it with a photosensitizer (PS). This classical, simple strategy was already employed with the $\mathrm{Fe}-\mathrm{o}-\mathrm{OH}$, for which we showed that with both an inorganic $\left(\operatorname{Ir}(\mathrm{ppy})_{3}\right.$, Fig. 5) or an organic (9-CNA, Fig. 5) sensitizer, catalysis for CO production was enhanced. ${ }^{13}$ Beyond a better absorption in the visible range, the use of these two PSs greatly improved both the catalytic selectivity, with no or negligible amount of $\mathrm{H}_{2}$ formed, and the stability of the system, since CO formation increased linearly with irradiation time. This was also the first example of the association of an abundant metal-based catalyst and a low-cost organic sensitizer (9-CNA, Fig. 5). In the case of Fe- $p$-TMA, the use of $\operatorname{Ir}(\mathrm{ppy})_{3}$ as PS turned out to be even more remarkable. Indeed this system could realize the eight-electron reduction of $\mathrm{CO}_{2}$ to $\mathrm{CH}_{4}$ at ambient temperature and pressure upon visible light irradiation. ${ }^{51}$ Starting from $\mathrm{CO}_{2}$ as a substrate, $\mathrm{CO}$ is an intermediate product and the selectivity towards $\mathrm{CH}_{4}$ was $17 \%$. When using CO directly as the substrate, simply by saturating the solution with the gas, the formation of $\mathrm{CH}_{4}$ was obtained with a selectivity above $80 \%$, with $\mathrm{H}_{2}$ being the only by-product detected. To circumvent the use of a noble-metal based PS, we very recently replaced it by a phenoxazine-based organic PS (Phen, Fig. 5). ${ }^{52}$ In this case too, $\mathrm{CO}_{2}$ or $\mathrm{CO}$ could be used as a starting material to form $\mathrm{CH}_{4}$. Compared with Ir $(\text { ppy })_{3}$, Phen is significantly more efficient as a PS, producing, under similar conditions, almost twice the amount of $\mathrm{CH}_{4}$ with a quantum yield multiplied by $c a$. three. In both cases, the rationale resided in the high reducing character of the triplet excited state of, respectively, $\operatorname{Ir}(\mathrm{ppy})_{3}\left(E^{\circ}\left(\operatorname{Ir}(\mathrm{IV}) /{ }^{3} \operatorname{Ir}(\mathrm{III})^{*}\right)=\right.$ $-1.73 \mathrm{~V}$ vs. SCE, Table 2) and accumulation of the Fe(II)-CO intermediate. In other words, the key to produce methane lies in the ability to activate the $\mathrm{CO}$ bound to the Fe(II) complex, using highly reducing species before the $\mathrm{CO}$ could be released

Table 2 Standard redox potentials (V vs. SCE) for electron donors and sensitizers

Sacrificial electron donors (SD) (in acetonitrile for amines, in $\mathrm{H}_{2} \mathrm{O}$ for EDTA)

\begin{tabular}{llllll}
\hline & TEA $^{61}$ & TEOA $^{62}$ & DiPEA $^{63}$ & EDTA $^{62}$ & BIH $^{64}$ \\
\hline$E_{\mathrm{ox}}\left(\mathrm{SD}^{\circ+} / \mathrm{SD}\right)$ & +1.0 & +0.82 & +0.5 & 0.92 & +0.33
\end{tabular}

Photosensitizers (PS) (in acetonitrile)

\begin{tabular}{|c|c|c|c|c|}
\hline & $\mathrm{PS}^{+} / \mathrm{PS}^{*}$ & $\mathrm{PS}^{*} / \mathrm{PS}^{-}$ & $\mathrm{PS}^{+} / \mathrm{PS}$ & $\mathrm{PS} / \mathrm{PS}^{-}$ \\
\hline $9-\mathrm{CNA}^{65}$ & & & & -1.58 \\
\hline $\mathrm{PP}^{53}$ & & & & $-0.66^{a}$ \\
\hline Phen $^{66}$ & -1.80 & & +0.65 & \\
\hline $\mathrm{Ru}(\mathrm{bpy})_{3}{ }^{61}$ & -0.81 & +0.77 & +1.29 & -1.33 \\
\hline $\operatorname{Ir}(p p y)_{3}{ }^{61}$ & -1.73 & +0.31 & +0.77 & -2.19 \\
\hline $\operatorname{Ir}(\text { ppy })_{2}(\mathrm{bpy})^{67}$ & -0.85 & +0.68 & +1.25 & -1.42 \\
\hline
\end{tabular}

\footnotetext{
${ }^{a}$ From its monoanionic to its dianionic form.
}

from the metal centre. For all of these studies, GC/MS experiments were performed under a ${ }^{13} \mathrm{CO}_{2}$ or ${ }^{13} \mathrm{CO}$ atmosphere, respectively, and confirmed that the produced $\mathrm{CH}_{4}$ originated from $\mathrm{CO}_{2}$ or $\mathrm{CO}$, respectively. Until now, we have not been able to achieve methane formation at an electrode since there is no accumulation of the $\mathrm{Fe}(\mathrm{II})$ species that are necessary to react with CO.

\section{Photoinduced $\mathrm{CO}_{2}$ reduction in aqueous solutions}

Another important physical property of Fe- $p$-TMA is its solubility in aqueous solutions thanks to its positively charged trimethylammonio groups. Water as a solvent remains a challenge in the catalytic transformation of $\mathrm{CO}_{2}$ with molecular compounds, in particular for solubility reasons, but also for selectivity issues with the competitive $\mathrm{H}_{2}$ evolution. $\mathrm{CO}_{2}$ solubility is much lower in water than in most commonly used organic solvents (e.g. by a factor of ca. 5 when compared to DMF or ACN) and both water-soluble catalysts and visible-light PSs are rare. However, we demonstrated that a typical organic dye, namely purpurin (PP, Fig. 5), could be employed as a PS in combination with Fe- $p$-TMA in aqueous solution (containing $10 \%$ acetonitrile) to achieve the production of $\mathrm{CO}$ from $\mathrm{CO}_{2}$ reduction over 2 days of irradiation. ${ }^{53}$ The catalytic process was, in this case, limited by progressive PP degradation, since catalytic activity could be restored upon adding fresh sensitizer.

Even though the rate remained modest, the selectivity towards CO was excellent (above 95\%) with very little formation of $\mathrm{H}_{2}$. This illustrates the remarkable potential of Fe- $p$ TMA and its high affinity for $\mathrm{CO}_{2}$. To solve PS degradation, we also tried to employ a water-compatible analogue of $\operatorname{Ir}(\mathrm{ppy})_{3}$, namely $\operatorname{Ir}(\mathrm{ppy})_{2}$ (bpy) (Fig. 5). In acetonitrile/ $\mathrm{H}_{2} \mathrm{O}(3: 7 \mathrm{v} / \mathrm{v})$ solution, upon visible-light irradiation, $\mathrm{CO}$ was the major $\mathrm{CO}_{2}$ reduction product (75\% selectivity), with $\mathrm{H}_{2}$ and $\mathrm{CH}_{4}$ formed in minor amounts (16\% and $9 \%$ selectivity, respectively). The efficiency of the catalytic system was, however, severely limited by two factors, first the low $\mathrm{CO}_{2}$ solubility and most importantly by the instability of the iridium PS in the presence of $\mathrm{CO}$, because of a deleterious ligandation/deligandation process and concomitant loss of activity. Even though the performances and/or stability in aqueous solutions remained modest, these works can be considered as a proof of concept and could open the door to new developments of aqueous photocatalytic processes.

\section{Mechanism under photochemical conditions}

A global photochemical catalytic scheme is presented in Fig. 6 . Electron injection in the system is insured by a photochemical event (Photo-ET) through oxidative quenching reaction with the PS. Once the catalyst active form, $\mathrm{Fe}(0)$, is formed, it combines with $\mathrm{CO}_{2}$ to form a $\mathrm{Fe}(\mathrm{II})-\mathrm{CO}_{2}$ adduct. In acidic conditions, i.e. if protons are readily available, a competitive $\mathrm{H}_{2}$ formation may occur through a hydride formation to form $\mathrm{Fe}(0)$. Otherwise, $\mathrm{Fe}(\mathrm{II})-\mathrm{CO}_{2}$ leads to $\mathrm{Fe}(\mathrm{II})-\mathrm{CO}$ and the release of $\mathrm{CO}$, giving back $\mathrm{Fe}(\mathrm{II})$ and closing the cycle. Under conditions exposed earlier, $\mathrm{CH}_{4}$ formation is accomplished through a 


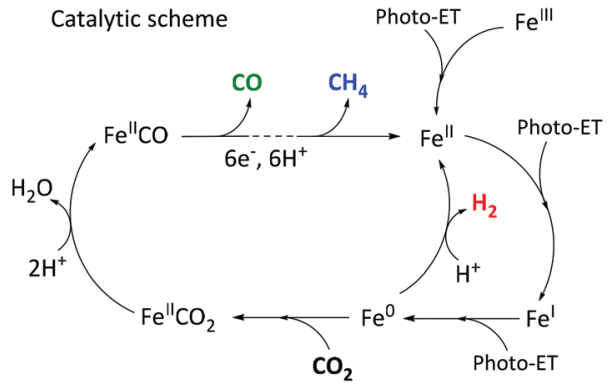

Photoinduced Electron Transfer

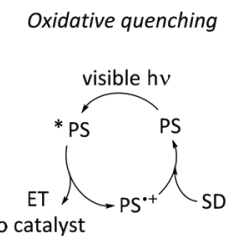

Reductive quenching

or

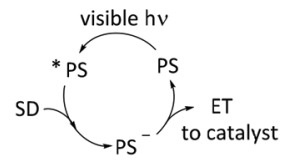

Fig. 6 Schematic mechanism for the multi-electrons multi-protons reduction of $\mathrm{CO}_{2}$ to $\mathrm{CO}$ and then $\mathrm{CH}_{4}$ by tandem catalysis, implying a molecular sensitizer (PS), a sacrificial electron donor (SD) and a Fe-porphyrin as catalyst.

mechanistic pathway that has not yet been deciphered and for which we are conducting intensive ongoing experimental and theoretical studies.

\section{Conclusions and perspectives}

We have illustrated in this perspective how a careful, rational mechanistic approach may bring a valuable contribution to the understanding of the intrinsic factors governing electrochemical $\mathrm{O}_{2}$ activation and photostimulated $\mathrm{CO}_{2}$ reduction by tetraphenyl Fe porphyrin catalysts under mild conditions.

In the case of dioxygen, such an approach could help in monitoring the partially reduced oxygen species (PROS) produced during $\mathrm{O}_{2}$ reduction, thus generating high valent species, such as Fe(Iv) ${ }^{\circ+}$-oxo or Fe(v)-oxo (Fig. 3). These highly oxidizing species could serve as an oxidant for catalytic reac-tion

with an organic substrate. It is clear that controlling the competition between the reaction of these crucial high-valent intermediates with the substrate (upper left part in Fig. 3) and their reduction by electron transfer from the electrode (leading to the $4 \mathrm{e}^{-}$reduction product, $\mathrm{H}_{2} \mathrm{O}$, Fig. 3 ) is still a challenging issue. Designing new Fe porphyrins bearing rationally designed functional groups on the second coordination sphere and/or grafted on the electrode surface with various spacers may help prevent unwanted reactions and prevent triggering oxidation reactions of the

substrates. Ultimately, such approaches will also be beneficial towards the transposition of the oxidation strategy to photoinduced processes, opening a route to sustainable oxidation processes using only solar light. Then, helped by the fundamental understanding and control of $\mathrm{O}_{2}$ activation, one can foresee the development of industrial synthetic processes that will take due account of environmental and economic constraints.

Regarding the carbon dioxide photostimulated catalysis with visible light, Fe porphyrins have also emerged as versatile and highly active catalysts. Much remains to be done in terms of mechanistic studies, especially for the understanding of the $8 \mathrm{e}^{-} / 8 \mathrm{H}^{+}$reduction to methane, which will involve the combination of spectroscopic studies, such as time-resolved infrared spectroscopy, and quantum calculations. Such studies are a necessary step towards expanding the range of products that could be obtained from the catalytic conversion of $\mathrm{CO}_{2}$. Fuels, such as methanol, and multi-carbon products are among the most important targets that currently remain inaccessible. In this connection, developing multi-metallic complexes for triggering cooperativity between metal centres, as naturally performed by enzymes, such CO dehydrogenase (CODH) should be explored. Another important aspect is to increase the efficiency of the photoprocesses through a better collection of the light (quantum efficiencies remain low when using molecular sensitizers despite recent progress) and of the chargetransfer reactions. Several strategies may be envisioned, among which the association of the catalysts to photoelectrodes and the development of metal-organic frameworks ${ }^{68}$ seem appealing. The replacement of amines as sacrificial electron donors by water or by developing valuable oxidation process that would be coupled to $\mathrm{CO}_{2}$ reduction is also an important challenge. Finally these studies pave the way towards solar-driven $\mathrm{CO}_{2}$ conversion employing water as a proton source, which could have a significant impact in changing current industries into a low carbon economy.

\section{Conflicts of interest}

The authors declare no competing financial interest.

\section{Acknowledgements}

Partial financial support to $M$. R. from the Institut Universitaire de France (IUF), from the French National Research Agency (ANR-116BS07-024-03, Cathymetoxy) to C. F. and from Labex Michem to E. A. M. are warmly thanked. Dr Heng Rao, Dr Mathilde Routier, Ms Celia Achaibou, Dr Rachel Oliveira and Dr Luciana C. Schmidt are gratefully acknowledged for the work accomplished in the lab on these topics.

\section{References}

1 A. A. Gewirth, J. A. Varnell and A. M. DiAscro, Chem. Rev., 2018, 118, 2313-2339.

2 M. L. Pegis, C. F. Wise, D. J. Martin and J. M. Mayer, Chem. Rev., 2018, 118, 2340-2391.

3 J. P. Collman, R. Boulatov, C. J. Sunderland and L. Fu, Chem. Rev., 2004, 104, 561-588. 
4 M. Momenteau and C. A. Reed, Chem. Rev., 1994, 94, 659698.

5 I. Bhugun, D. Lexa and J.-M. Savéant, J. Am. Chem. Soc., 1994, 116, 5015-5016.

6 C. Costentin, M. Robert and J.-M. Savéant, Chem. Soc. Rev., 2013, 42, 2423-2436.

7 C. Costentin, M. Robert and J.-M. Savéant, Acc. Chem. Res., 2015, 48, 2996-3006.

8 R. Francke, B. Schille and M. Roemelt, Chem. Rev., 2018, 118, 4631-4701.

9 C. Costentin, G. Passard and J.-M. Savéant, J. Am. Chem. Soc., 2015, 137, 5461-5467.

10 A. Maurin and M. Robert, J. Am. Chem. Soc., 2016, 138, 2492-2495.

11 A. Tatin, C. Comminges, B. Kokoh, C. Costentin, M. Robert and J.-M. Savéant, Proc. Natl. Acad. Sci. U. S. A., 2016, 113, 5526-5529.

12 J. Bonin, M. Chaussemier, M. Robert and M. Routier, ChemCatChem, 2014, 6, 3200-3207.

13 J. Bonin, M. Robert and M. Routier, J. Am. Chem. Soc., 2014, 136, 16768-16771.

14 H. Nakashima, J.-Y. Hasegawa and H. Nakatsuji, J. Comput. Chem., 2006, 27, 426-433.

15 S. Samanta, P. K. Das, S. Chatterjee and A. Dey, J. Porphyrins Phthalocyanines, 2015, 19, 92-108.

16 M. Tsuda and H. Kasai, Surf. Sci., 2007, 601, 5200-5206.

17 T. Ohta, P. Nagaraju, J.-G. Liu, T. Ogura and Y. Naruta, J. Biol. Inorg. Chem., 2016, 21, 745-755.

18 J. P. Collman, Acc. Chem. Res., 1977, 10, 265-272.

19 W. Zhang, W. Lai and R. Cao, Chem. Rev., 2017, 117, 37173797.

20 J. Rosenthal and D. G. Nocera, Acc. Chem. Res., 2007, 40, 543-553.

21 S. Samanta, K. Sengupta, K. Mittra, S. Bandyopadhyay and A. Dey, Chem. Commun., 2012, 48, 7631-7633.

22 C. T. Carver, B. D. Matson and J. M. Mayer, J. Am. Chem. Soc., 2012, 134, 5444-5447.

23 Q. He, T. Mugadza, G. Hwang and T. Nyokong, Int. J. Electrochem. Sci., 2012, 7, 7045-7064.

24 B. D. Matson, C. T. Carver, A. Von Ruden, J. Y. Yang, S. Raugei and J. M. Mayer, Chem. Commun., 2012, 48, 11100-11102.

25 S. Amanullah, P. K. Das, S. Samanta and A. Dey, Chem. Commun., 2015, 51, 10010-10013.

26 D. J. Wasylenko, C. Rodríguez, M. L. Pegis and J. M. Mayer, J. Am. Chem. Soc., 2014, 136, 12544-12547.

27 M. L. Pegis, B. A. McKeown, N. Kumar, K. Lang, D. J. Wasylenko, X. P. Zhang, S. Raugei and J. M. Mayer, ACS Cent. Sci., 2016, 2, 850-856.

28 K. Mittra, S. Chatterjee, S. Samanta and A. Dey, Inorg. Chem., 2013, 52, 14317-14325.

29 S. Samanta, K. Mittra, K. Sengupta, S. Chatterjee and A. Dey, Inorg. Chem., 2013, 52, 1443-1453.

30 J. P. Collman, N. K. Devaraj, R. A. Decréau, Y. Yang, Y.-L. Yan, W. Ebina, T. A. Eberspacher and C. E. D. Chidsey, Science, 2007, 315, 1565.
31 J. P. Collman, A. Dey, Y. Yang, S. Ghosh and R. A. Decréau, Proc. Natl. Acad. Sci. U. S. A., 2009, 106, 10528.

32 K. Sengupta, S. Chatterjee, S. Samanta, S. Bandyopadhyay and A. Dey, Inorg. Chem., 2013, 52, 2000-2014.

33 J. Chlistunoff and J.-M. Sansiñena, J. Phys. Chem. C, 2014, 118, 19139-19149.

34 T. D. Rapson, R. Kusuoka, J. Butcher, M. Musameh, C. J. Dunn, J. S. Church, A. C. Warden, C. F. Blanford, N. Nakamura and T. D. Sutherland, J. Mater. Chem. A, 2017, 5, 10236-10243.

35 C. Costentin, H. Dridi and J.-M. Savéant, J. Am. Chem. Soc., 2015, 137, 13535-13544.

36 P.-J. Wei, G.-Q. Yu, Y. Naruta and J.-G. Liu, Angew. Chem., Int. Ed., 2014, 53, 6659-6663.

37 S. Chatterjee, K. Sengupta, S. Bandyopadhyay and A. Dey, J. Mater. Chem. A, 2016, 4, 6819-6823.

38 R. Z. Snitkoff, N. Levy, I. Ozery, S. Ruthstein and L. Elbaz, Carbon, 2019, 143, 223-229.

39 M. L. Rigsby, D. J. Wasylenko, M. L. Pegis and J. M. Mayer, J. Am. Chem. Soc., 2015, 137, 4296-4299.

40 K. Sengupta, S. Chatterjee, S. Samanta and A. Dey, Proc. Natl. Acad. Sci. U. S. A., 2013, 110, 8431-8436.

41 S. Chatterjee, K. Sengupta, S. Samanta, P. K. Das and A. Dey, Inorg. Chem., 2015, 54, 2383-2392.

42 S. Chatterjee, K. Sengupta, S. Samanta, P. K. Das and A. Dey, Inorg. Chem., 2013, 52, 9897-9907.

43 K. Sengupta, S. Chatterjee and A. Dey, ACS Catal., 2016, 6, 6838-6852.

44 S. Bhunia, A. Rana, P. Roy, D. J. Martin, M. L. Pegis, B. Roy and A. Dey, J. Am. Chem. Soc., 2018, 140, 94449457.

45 R. Oliveira, W. Zouari, C. Herrero, F. Banse, B. Schöllhorn, C. Fave and E. Anxolabéhère-Mallart, Inorg. Chem., 2016, 55, 12204-12210.

46 S. Chatterjee, K. Sengupta, B. Mondal, S. Dey and A. Dey, Acc. Chem. Res., 2017, 50, 1744-1753.

47 T. Dhanasekaran, J. Grodkowski, P. Neta, P. Hambright and E. Fujita, J. Phys. Chem. A, 1999, 103, 7742-7748.

48 J. Grodkowski, D. Behar, P. Neta and P. Hambright, J. Phys. Chem. A, 1997, 101, 248-254.

49 H. Takeda, C. Cometto, O. Ishitani and M. Robert, ACS Catal., 2017, 7, 70-88.

50 H. Rao, J. Bonin and M. Robert, Chem. Commun., 2017, 53, 2830-2833.

51 H. Rao, L. C. Schmidt, J. Bonin and M. Robert, Nature, 2017, 548, 74-77.

52 H. Rao, C.-H. Lim, J. Bonin, G. M. Miyake and M. Robert, J. Am. Chem. Soc., 2018, 140, 17830-17834.

53 H. Rao, J. Bonin and M. Robert, ChemSusChem, 2017, 10, 4447-4450.

54 H. Rao, J. Bonin and M. Robert, J. Phys. Chem. C, 2018, 122, 13834-13839.

55 E. Anxolabéhère, G. Chottard and D. Lexa, New J. Chem., 1994, 18, 889-899.

56 C. Costentin, G. Passard, M. Robert and J.-M. Savéant, Proc. Natl. Acad. Sci. U. S. A., 2014, 111, 14990-14994. 
57 I. Azcarate, C. Costentin, M. Robert and J.-M. Savéant, J. Am. Chem. Soc., 2016, 138, 16639-16644.

58 J. Bonin, A. Maurin and M. Robert, Coord. Chem. Rev., 2017, 334, 184-198.

59 A. J. Esswein and D. G. Nocera, Chem. Rev., 2007, 107, 4022-4047.

60 Y. Pellegrin and F. Odobel, C. R. Chim., 2017, 20, 283-295.

61 C. K. Prier, D. A. Rankic and D. W. C. MacMillan, Chem. Rev., 2013, 113, 5322-5363.

62 A.-M. Manke, K. Geisel, A. Fetzer and P. Kurz, Phys. Chem. Chem. Phys., 2014, 16, 12029-12042.

63 C. D. McTiernan, M. Morin, T. McCallum, J. C. Scaiano and L. Barriault, Catal. Sci. Technol., 2016, 6, 201-207.
64 E. Hasegawa, S. Takizawa, T. Seida, A. Yamaguchi, N. Yamaguchi, N. Chiba, T. Takahashi, H. Ikeda and K. Akiyama, Tetrahedron, 2006, 62, 6581-6588.

65 J. Eriksen and C. S. Foote, J. Phys. Chem., 1978, 82, 26592662.

66 Y. Du, R. M. Pearson, C.-H. Lim, S. M. Sartor, M. D. Ryan, H. Yang, N. H. Damrauer and G. M. Miyake, Chem. - Eur. J., 2017, 23, 10962-10968.

67 J. I. Goldsmith, W. R. Hudson, M. S. Lowry, T. H. Anderson and S. Bernhard, J. Am. Chem. Soc., 2005, 127, 7502-7510.

68 S. Lin, C. S. Diercks, Y.-B. Zhang, N. Kornienko, E. M. Nichols, Y. Zhao, A. R. Paris, D. Kim, P. Yang, O. M. Yaghi and C. J. Chang, Science, 2015, 349, 1208-1213. 